\title{
Disintegration of power grid as part of the task of increasing functionality of electric system
}

\author{
Bekzhan Mukatov ${ }^{*}$, Alexander Fishov ${ }^{2}$ \\ ${ }^{1}$ JSC “KEGOC”, National Dispatch Center of the System Operator, Z00T2D0, Astana, Kazakhstan \\ ${ }^{2}$ Novosibirsk State Technical University, 630073, Novosibirsk, Russia
}

\begin{abstract}
When operating electric power systems there are often situations in which the power systems operation is inevitable with reduced reliability or, otherwise, with incomplete functionality where functionality is the set of functions provided by the power system and the quality of their performance. With the mass input of distributed small generation in grids of almost all voltage classes it is necessary to solve the problem of ensuring stability in previously passive distribution networks. The traditional approach based on the "struggle" to maintain synchronism between power plants in the distribution networks is associated with a number of difficulties, which causes to apply another approach to control modes in distribution networks. Complication of the power grid, automatic devices, increase in possible variations of modes, and tendency to maximize the use of production assets lead to an increase in the complexity of tasks solved by dispatch centers. In this regard, it is important to note that availability of cascade failures in power systems speaks of the urgency of the task of ensuring the survivability of energy supply systems both globally and locally. The paper shows how disintegration of the power grid can solve the task of ensuring the functionality of traditional power systems and help to create favorable conditions for distributed small generation integration into the integrated electric power system.
\end{abstract}

\section{The study of potential of power grid disintegration}

In traditional power grids functionality is provided by the integrity of structure and system mode, i.e. stability of parallel operation of all power plants. To do this restrictions are imposed on the power transmitted over the network in the form of capacity reserves, and a complicated emergency control system is maintained. In such electric power systems (EPS) disintegration (division of the power grid into parts) refers to exceptional measures of impact on the mode in order to ensure survivability of EPS.

Currently, development and operation of power systems are based on the invariance of the network switching scheme to their modes. At the same time, the network disintegration potential is underused to ensure reliability of the power supply system and ensure its survivability. Disintegration of network is used to separate the district or power plant for isolated work with an approximately balanced load in a predetermined section, as well as to terminate the asynchronous mode in section that connects nonsynchronous parts.

In networks with an adaptive structure the reliability and quality of power supply is more determined by the system's ability to balance the separation and post reduction of the system integrity. Functionality may to a considerable extent be provided by changing the configuration of power grid with allocation of balanced subsystems to isolated work depending on the current mode. Unlike traditional EPS where the integral structure is a carrier of reliability, in adaptive EPS due to the development of the power system survivability feature preventive disintegration becomes the basis of reliability [1,2].

Disintegration of power grid with reduced functionality is capable of raising its level or restoring it completely due to the effective use of EPS internal reserves of structural nature. These reserves include:

- the use of the regulating effect of load in frequency and voltage;

- increase in permissible power flows corresponding to the regulatory stability reserves which can be achieved by reducing irregular fluctuations, by reducing (up to complete elimination) the total consumption in one of the intersectional subsystem;

- forced power flow to relieve overload on the electric power line due to the load of other unloaded elements.

Disintegration of EPS can be used to re-commute the circuit in such a way that the system survivability increases under severe system conditions (for example, deep frequency reduction in the region), as well as in modes where $n-1$ criterion is not met. This is especially important in the power system operating conditions with reduced stability reserves.

Currently, with a decrease in functionality due to non-compliance with the requirements for stability reserves, i.e. in increased risk modes (IRM), the 
possibility of implementing such mode, as a rule, is provided by Emergency Control Automatics (ECA) with an impact on load shedding or generation. Thus, in case of system integrity and line shutdown in section 1 or generator in subsystem 2 (Fig. 1a), the Stability Control Schemes (SCS) will unload the section 1 due to the load shedding in subsystem 2 .
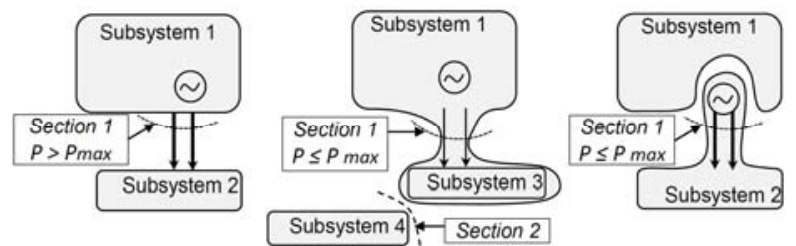

Fig. 1. IRM (a) and EPS disintegration modes that exclude IRM (b, c), where P - section loading in IRM, P max - the maximum permissible flow in section.

IRM can be excluded or passed with more functionality due to the power grid disintegration. In Fig. 1 shows the options of power grid disintegration to demonstrate the effectiveness of its application to improve functionality in IRM.

According to [3] permissible overflow on static stability with normative reserves on active power $\left(k_{p}\right)$ in section is calculated according to the formula (1):

$$
P=P_{\lim } \cdot\left(1-k_{p}\right)-\Delta P_{i f}
$$

where $P_{\text {lim }}$ - active-power flow that is limit according to non-periodic static stability in the reviews section; $P$ - the flow in section in the reviewed mode, $\Delta P_{i f}$ - the amplitude of irregular fluctuations of active power in this section.

If the actual data is missing $\Delta R_{i f}$ shall be calculated according to the formula:

$$
\Delta P_{i f}=k \cdot \sqrt{\frac{P_{l 1} \cdot P_{H 2}}{P_{l 1}+P_{l 2}}},
$$

where $P_{l 1}, P_{l 2}$ - total load capacities on each side of the section, $k$ - coefficient that is equal to 1.5 for manual control and 0.75 for automatic control (restriction) of power flow in section.

After reconfiguration with division of subsystem 2 into two subsystems ( 3 and 4 ), $\Delta P_{i f}$ in (1) decreases as the total capacity of the subsystem 3 is less than the power of the original subsystem 2 . In case of power unbalance in subsystem 4, the necessity for disconnecting consumers can be completely or partially eliminated by using the regulating effect of the load in frequency and voltage.

Table 1 shows the volumes of the ECA control actions with reliability provided by traditional SCS, as well as disintegration according to the schemes shown in Fig. 1b), c) for the original characteristic mode of the Kazakhstan power grid (Figure 1a), where subsystem 1 is the northern part of Kazakhstan power grid, 2 is the southern part of Kazakhstan power grid and the EPS of Uzbekistan and Kyrgyzstan.
Calculations were carried out using "RastrWin" and "Mustang" software complexes for modes calculation.

Table 1. The volume of control actions in case of designed

\begin{tabular}{|c|c|c|c|c|c|c|c|}
\hline \multicolumn{2}{|c|}{ Designed disturbances } & \multicolumn{3}{|c|}{$\begin{array}{c}\text { Power transmission } \\
\text { line shutdown in } \\
\text { section } 1\end{array}$} & \multicolumn{3}{|c|}{$\begin{array}{c}\text { Shutdown of } 200 \mathrm{MW} \\
\text { generation in } \\
\text { subsystem } 2\end{array}$} \\
\hline \multirow{2}{*}{\multicolumn{2}{|c|}{$\begin{array}{c}\text { Method of reliability } \\
\text { assurance }\end{array}$}} & \multirow[b]{2}{*}{$\operatorname{sCs}$} & \multicolumn{2}{|c|}{ Reconfiguration } & \multirow[b]{2}{*}{ SCS } & \multicolumn{2}{|c|}{ Reconfiguration } \\
\hline & & & $\begin{array}{l}\text { According } \\
\text { to the }\end{array}$ & $\begin{array}{l}\text { According } \\
\text { to the }\end{array}$ & & $\begin{array}{l}\text { According } \\
\text { to the }\end{array}$ & $\begin{array}{l}\text { According } \\
\text { to the }\end{array}$ \\
\hline \multirow[b]{3}{*}{ 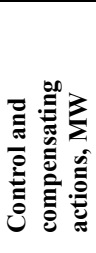 } & $\begin{array}{l}\text { Shutdown of } \\
\text { generators }\end{array}$ & 0 & 0 & 200 & 0 & 0 & 0 \\
\hline & Load shedding & 400 & 250 & 0 & 200 & 50 & 0 \\
\hline & $\begin{array}{l}\text { Compensation } \\
\text { of unbalance } \\
\text { due to } \\
\text { regulating } \\
\text { effect of load }\end{array}$ & 0 & 0 & 200 & 0 & 0 & 200 \\
\hline
\end{tabular}
disturbances

\section{Decentralized reconfiguration of active electrical distribution network}

Active increase in the number of distributed small generation (DSG) facilities with their inclusion in parallel operation of the power grid poses the problem of development of technologies for modes management to ensure their effective integration into EPS [4-8].

Input of DSG in the previously passive power distribution networks (DN) radically alters their original properties, turning the passive $\mathrm{DN}$ into active power grids - the power systems [9-13].

In view of the existing difficulties in implementation of centralized management of modes of the active distribution network, the existing traditional management technology is too costly for systems with DSG and unable to fully solve the tasks. Taking into account the large number of participants of the electricity and related services market acting for their own sake, it is appropriateness of organizing distributed management of power grid modes with DSG based on multi-agent technologies [14-19].

The source [20] proposes decentralized algorithms for searching sections of the network and recommutating the circuit while preserving integrity of the power system to improve functionality of the power supply systems. Then, in the enlarged form, the results of testing of distributed algorithms for reconfiguring electrical network on specially designed software modeling behavior of agents of the multi-agent system (MAS) are presented.

\subsection{Multi-agent reconfiguration when network element is overloaded}

According to example of the circuit representing 220$110 \mathrm{kV}$ electric networks of the Western part of the EPS of the Republic of Kazakhstan (Fig. 2), a multiagent search of the network structure excluding overload of the power lines was performed. 


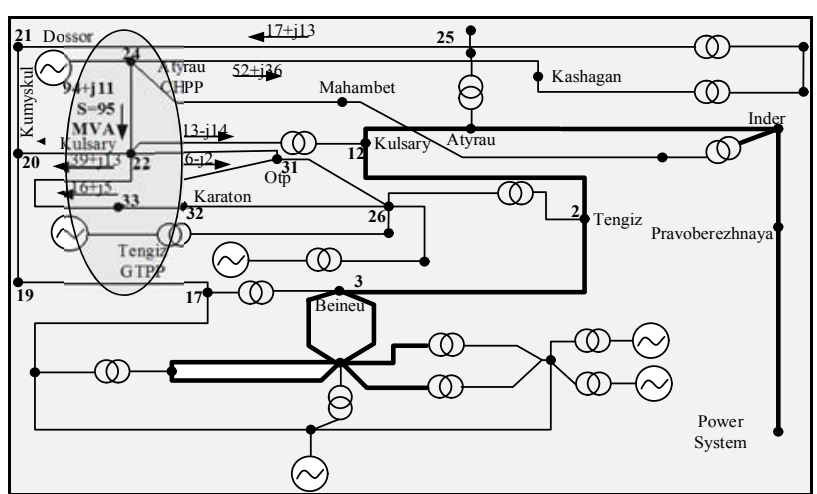

Fig.2. Initial conditions of EPS of the Western part of EPS of the Republic of Kazakhstan.

In the original scheme, the overhead line between nodes 22 and 24 is overloaded (Atyrau TPP - Kulsary SS).

The MAS performed reconfiguration, as a result of which bars were electrically separated at the Kulsary substation and part of the overhead line was switched to 1 busbar, the other part to 2 busbar. Taking into account the possible combinations in distribution of loads on the bars, the minimum possible load was transferred to the 2 busbar with preservation of communication with transformer of Kulsary substation. The result of reconfiguration is shown in Fig.3.

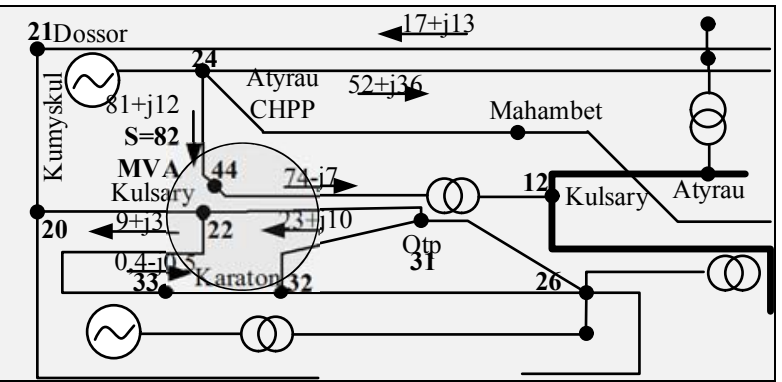

Fig.3. EPS fragment after reconfiguration. Overload of line of Atyrau TPP - Kulsary SS was eliminated.

\subsection{Multi-agent disintegration of the power grid}

To test adequacy of the MAS operation in case of adaptive network division, a study was conducted using the example of electrical network of the Kazakhstan's power grid southern regions.

Fig. 4 shows the result of simulation of actions of agents with perturbation in external network in a characteristic winter maximum of consumption.

Dotted lines mark out the nodes that form areas passing into the insular mode of operation. To ensure the balanced state of one of the subsystems bars of Mirgalimsay substation were separated.

The simulation results show that fission cross sections change within a day. Division by bars was performed in three nodes (Chulak, Zhambyl, Shelek substations) at the hour of night minimum of consumption.

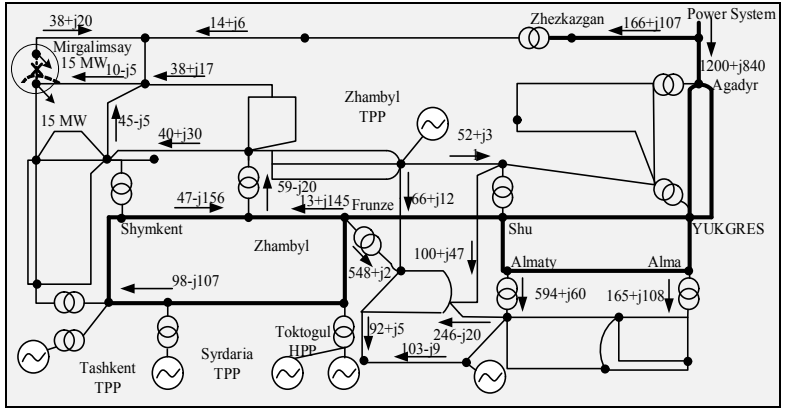

Fig.4. Result of MAS operation on searching for fission cross sections per hour of maximum.

To compare the results of MAS operation with traditional automatics, the fission cross sections (double continuous line) performed by the centralized division automatics are shown in the same figures.

In the scheme of a certain MAS division, the amount of disconnected load in the southern part of the Kazakhstan's power grid is about 350 and $200 \mathrm{MW}$ at the time of maximum and minimum, respectively. The volume of restrictions during operation of the traditional division automatics in similar hours is more than 2 times higher.

\section{Preventive disintegration in active electrical networks}

An analysis of transient modes when connecting small generation to electric network and short circuit in the power system [2] showed that due to strong connections between subsystems there is a high probability of occurrence of unacceptable shock moments on synchronous machine shafts, disturbances of dynamic stability that are capable of causing their damage. Moreover, the switched-off short-circuit currents increase significantly, relay protection becomes more complicated [20].

These negative phenomena can be minimized due to the new way of emergency control - the accelerated termination of synchronous operation of DSG from integrated electric power system (preventive division) to disconnection of the short-circuit places.

Figure 5 shows the values of cutoff currents of short-circuit and dynamic moments on the shafts of generators $\mathrm{G} 1, \mathrm{G} 2$, obtained as a result of simulation for various control methods in case of short-circuit.

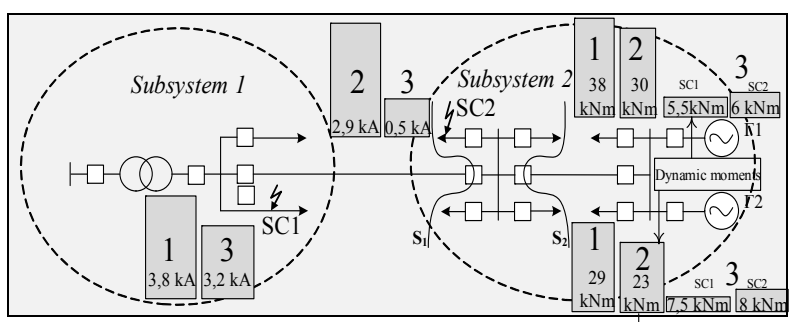

Fig.5. Cutoff currents of short circuit and dynamic moments: 1 - in case of short circuit 1 without network division, 2 - in case of short circuit 2 with network division by automation of the termination of an asynchronous mode action, 3- in case of short circuit 1, 2 with preventive network division in sections $\mathrm{S} 1, \mathrm{~S} 2$ 
Results of the research show that the preventive balanced disintegration of the network of power systems connection according to fixed sections ensures reduction of disconnected short-circuit currents, does not change the conditions determining the operation of the relay protection of a high-power electric system in the absence of parallel operation, eliminates the threat of unacceptable moments on synchronous generator shafts, prevents the emergence of asynchronous modes, reduces the volumes of load shedding to prevent the development of accidents.

\section{Conclusion}

The potential of the disintegration of the electric grid was studied using the example of Kazakhstan's power system. The results of the research demonstrate the possibility of reducing the amount of disconnected power consumers in case of emergency disturbances by $400 \mathrm{MW}$, by increasing acceptable load flow in the overloaded sections and using the regulating effect of the loads obtained during network reconfiguration.

The conducted researches of multi-agent algorithms of the electric networks reconfiguration show the prospects and efficiency of their application for providing the functionality of power systems. For the examples considered, the separation of subsystems in the sections received by MAS in emergency load flows, makes it possible to reduce the amount of disconnected power for consumers up to $350 \mathrm{MW}$, comparing to traditional automatics.

The results of simulation of the automatic preventive islanding demonstrate its effectiveness in systems with DSG when emergency disturbances can cause shock dynamic moments and a threat to dynamic stability. In the low-power subsystem, a six-fold decrease in the disconnected short-circuit current is observed, as well as at least a three-fold decrease in the dynamic moments on the synchronous machine shafts.

\section{References}

1. A.G. Fishov, B.B. Mukatov Bulletin of Tomsk Polytechnic University. Engineering of geological resources, №9. - P. 143-152. (2015).

2. B.B. Mukatov, A.G. Fishov, N.A. Kardzhaubayev Reports of the Academy of Sciences of the Higher School of the Russian Federation, № 4. - P. 94-104. (2015).

3. Methodological guidelines on the stability of power systems. (Approved by the Order of the Ministry of Energy of Russia dated June 30, 2003 № 277. M.: Publishing house "ENAS SC", 2004).

4. P.I. Bartolemey, T.Y. Panikovskaya, D.A. Chechushkov Joint symposium as part of the APEC project "Energy links between Russia and East Asia: development strategies in the XXI century". Irkutsk, P. 4-5. (2010).

5. A. Fishov, M. Shiller, A. Dekhterev, V. Fishov Journal of Energy and Power Engineering, №9 (1). P.59-67. (2015).
6. J.A. Pecas Lopes, N. Hatziargyriou, J. Mutale, P. Djapic, N. Jenkins. Electric Power Systems Research, №77. P. 1189-1203. (2007).

7. P.V. Ilyushin The possibility of ensuring reliable power supply of consumers from distributed generation facilities /research_commitets/ik_rus/c6_rus.

8. The potential benefits of distributed generation and rate-related issues that may impede their expansion (A study pursuant to section 1817, U.S. Department of Energy, 2007. https:// www.ferc.gov/legal/fed-sta/exp-study.pdf).

9. P.V. Ilyushin Energy Expert, №1. P 58-62. (2015) 10. Y.N Kucherov, P.V. Ilyushin Electro, №5. - P.27. (2014).

11. A.V. Pazderin, S.A. Yeroshenko, A.A. Karpenko, S.Y. Kokin, S.A. Dmitriyev, A.I. Haljasmaa Scientific review, № 6. P. 49-56. (2013).

12. G.S. Nudelman Modern trends in development of the systems of relay protection and automation of power systems: papers of the $4^{\text {th }}$ International Research and Practice Conference. Yekaterinburg: Publishing House "Russian National Committee SIGRE", P. 1-8. (2013).

13. B.B. Mukatov, A.G. Fishov, I.A. Yefremov Reports of the Academy of Sciences of the Higher School of the Russian Federation. № 4 P. 90-103. (2014).

14. D.A. Cohen Power and Energy Society General Meeting - Conversion and Delivery of Electrical Energy in the 21st Century, IEEE. P. 1-5. (2008). DOI: 10.1109/PES.2008.4596818.

15. A.G. Fishov, S.T. Ismoilov, S.S. Trufakin Modern trends in development of the systems of relay protection and automation of power systems: papers of the $4^{\text {th }}$ International Research and Practice Conference. Yekaterinburg: Publishing House "Russian National Committee SIGRE", P. 99-100. (2013).

16. J.M. Solanki. Integrated Computer-Aided Engineering, 17 (4). P. 331-346. (2010).

17. Chong Shao, Chen $\mathrm{Xu}$, Shan He, Xiangning Lin TENCON 2013 - 2013 IEEE Region 10 Conference (31194), P. 1-4. (2013).

18. S. D. J. McArthur, E. M. Davidson, V. M. Catterson, A. L. Dimeas, N. D. Hatziargyriou, F. Ponci, T. Multi-agent systems for power engineering applications - part 2: technologies, standards and tools for building multi-agent systems. IEEE Transactions on Power Systems, 22 (4). P. 1753-1759. (2007).

19. Arshad Saleem, Morten Lind, Manuela M. Veloso. 9th International Conference on Autonomous Agents and Multiagent Systems AAMAS. (2010).

20. B.B. Mukatov Managing division and restoration of network using expert technologies: Abstract of a Ph.D. Thesis: 05.14.02 (Novosibirsk. - 2016. -24 p). 